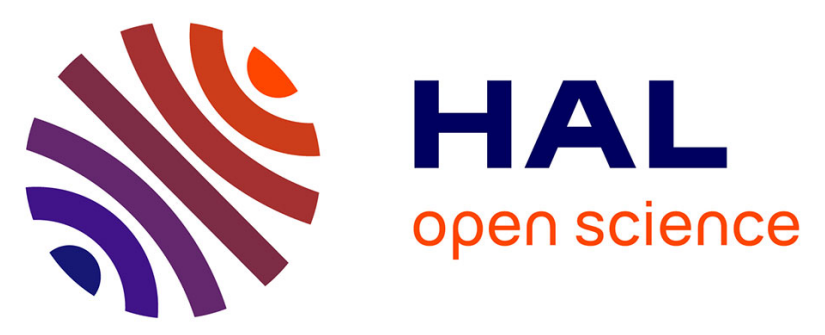

\title{
Effect of cerium concentration on corrosion resistance and polymerization of hybrid sol-gel coating on martensitic stainless steel
}

Jean-Baptiste Cambon, Florence Ansart, Jean-Pierre Bonino, Viviane Turq

\section{- To cite this version:}

Jean-Baptiste Cambon, Florence Ansart, Jean-Pierre Bonino, Viviane Turq. Effect of cerium concentration on corrosion resistance and polymerization of hybrid sol-gel coating on martensitic stainless steel. Progress in Organic Coatings, 2012, pp. 75, pp. 486-493. 10.1016/j.porgcoat.2012.06.005 . hal-00833772

\section{HAL Id: hal-00833772 \\ https://hal.science/hal-00833772}

Submitted on 13 Jun 2013

HAL is a multi-disciplinary open access archive for the deposit and dissemination of scientific research documents, whether they are published or not. The documents may come from teaching and research institutions in France or abroad, or from public or private research centers.
L'archive ouverte pluridisciplinaire HAL, est destinée au dépôt et à la diffusion de documents scientifiques de niveau recherche, publiés ou non, émanant des établissements d'enseignement et de recherche français ou étrangers, des laboratoires publics ou privés. 


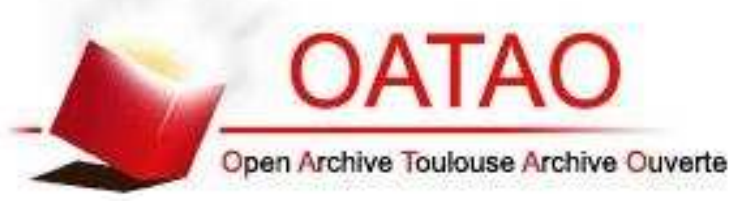

\section{Open Archive Toulouse Archive Ouverte (OATAO)}

OATAO is an open access repository that collects the work of Toulouse researchers and makes it freely available over the web where possible.

This is an author-deposited version published in: http://oatao.univ-toulouse.fr/ Eprints ID: 8743

To link to this article: DOI:10.1016/j.porgcoat.2012.06.005

Official URL: http://dx.doi.org/10.1016/j.porgcoat.2012.06.005

\section{To cite this version:}

Cambon, Jean-Baptiste and Ansart, Florence and Bonino, Jean-Pierre and Turq, Viviane Effect of cerium concentration on corrosion resistance and polymerization of hybrid sol-gel coating on martensitic stainless steel. (2012) Progress in Organic Coatings, pp. 75 ( $\mathrm{n}^{\circ}$ 4). pp. 486-493. ISSN 0300-9440

Any correspondence concerning this service should be sent to the repository administrator: staff-oatao@inp-toulouse.fr 


\title{
Effect of cerium concentration on corrosion resistance and polymerization of hybrid sol-gel coating on martensitic stainless steel
}

\author{
Jean-Baptiste Cambon*, Florence Ansart, Jean-Pierre Bonino, Viviane Turq \\ Institut Carnot CIRIMAT, Université de Toulouse, UMR CNRS 5085, 118 Route de Narbonne, 31062 Toulouse Cedex 9, France
}

\begin{abstract}
A B S T R A C T
Stainless steels are increasingly used in the aeronautics field for the manufacture of structural parts. One of them, the X13VD martensitic stainless steel (X12CrNiMoV12-3), known for its good mechanical properties, has a poor corrosion resistance in confined or severe environments. In the past years, $\mathrm{Cr}(\mathrm{VI})$ based pre-treatments have been currently used for corrosion protection of different metals, however, they are toxic and due to environmental regulations, they will be definitely banned in a near future. Alternatives to replace $\mathrm{Cr}(\mathrm{VI})$ show advantages and drawbacks considering key properties such as: corrosion resistance, adhesion of coatings, fatigue resistance, durability and reliability. However, some of their possible alternatives show high potential.

In this paper, a process was developed to improve the corrosion resistance of the martensitic stainless steel. Organic-inorganic hybrid coatings with different cerium concentrations were deposited onto stainless steel by sol-gel process. Corrosion resistance of the coatings was evaluated by electrochemical impedance measurements and it has been proved that cerium concentration of $0.01 \mathrm{M}$ into hybrid coating was an optimal content. Adhesion tests were also carried out by "nanoscratchtest" to characterize the coatings mechanical properties as a function of cerium concentration but results do not clearly show the influence of cerium for the coating adhesion toward the substrate. To try to correlate with the electrochemical properties, liquid ${ }^{29} \mathrm{Si}$ NMR spectroscopy was then performed to investigate hydrolysis and condensation reactions of sol-gel process, and by this method, it was demonstrated that for higher cerium concentration $(>0.01 \mathrm{M})$ there is a modification of the chemical structure of the sol-gel network.
\end{abstract}

\section{Introduction}

Metallic corrosion occurs as a result of chemical reactions between the metal surface and the environment, which converts the metal into its original ore. In the case of steel and aluminum, $\mathrm{Cl}^{-}, \mathrm{O}_{2}$ and $\mathrm{H}_{2} \mathrm{O}$ species, in addition to electron transport, play key roles in the corrosion process $[1,2]$. Generally, corrosion prevention technology uses one or more of the following methods. The first one is the addition of elements $(\mathrm{Cr}, \mathrm{Ni}$, etc.) in the metals to enrich the surface with a corrosion-resistant component during the corrosion process. This can be associated to the addition of aqueous inhibitors, which can be strongly adsorbed by chemical conversion treatment on the metal surface to prevent the reaction with the oxidizing agent. Chromates $(\mathrm{Cr}(\mathrm{VI}))$ are used as the most common compounds due to their efficiency in severe atmosphere and their low cost. But chromium based compounds are extremely toxic additives, carcinogen, mutagen and reprotoxic. So the use of chromates will be strictly prohibited in the next years [3].

\footnotetext{
* Corresponding author.

E-mail address: cambon@chimie.ups-tlse.fr (J.-B. Cambon).
}

Sol-gel coatings are one of the most promising alternative pretreatments, completely chrome-free with other advantages such as cost-effectiveness, low life-cycle environmental impact and simple application procedures. The potential application of sol-gel coatings as a corrosion protection system for metal substrates was highlighted 15 years ago by Guglielmi [4]. Then several works have been undertaken to make various sol-gel based protective coatings, as described in numerous recent reviews. Submicron metal oxide films inhibit corrosion by providing a chemically inert barrier to the diffusion of corrosive species, and the protective characteristics of sol-gel films containing $\mathrm{SiO}_{2}$ [5], $\mathrm{TiO}_{2}$ [6], $\mathrm{Al}_{2} \mathrm{O}_{3}$ [7], and $\mathrm{ZrO}_{2}$ [8], have been reported in various studies. Despite advantages of sol-gel processing, ceramic coatings suffer from several drawbacks: (a) high-temperature treatments $\left(>600^{\circ} \mathrm{C}\right)$ are required to decrease porosity and stabilize the films; (b) cracks occur during temperature fluctuations due to the brittle nature of ceramic films and incompatibility between the thermal expansion coefficients of metals and protective coatings; (c) thick $(>1 \mu \mathrm{m})$ crack-free sol-gel coatings are difficult to obtain. These limitations can be avoided by the development of hybrid organic-inorganic protective coatings, which combine the hardness, scratch resistance and thermal stability of the ceramic component with the flexibility, transparency and tunable adhesion of the organic substances [9-12]. 
Table 1

Chemical composition of CX13VD stainless steel (Fe balance).

\begin{tabular}{llllll}
\hline Element & $\mathrm{C}$ & $\mathrm{Cr}$ & $\mathrm{Ni}$ & Mo & $\mathrm{Va}$ \\
mol\% & 0.12 & 11.5 & 2.50 & 1.60 & 0.30 \\
\hline
\end{tabular}

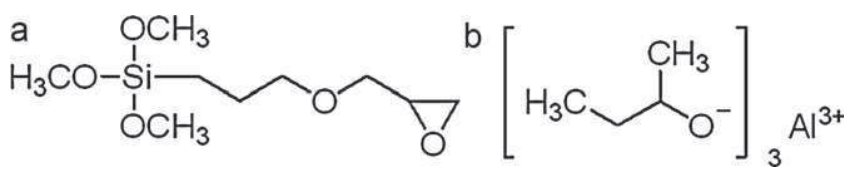

Fig. 1. Semi-developed formula of GPTMS (glycidoxyproil-trimethoxysilane) (a) and $\mathrm{Al}\left(\mathrm{O}^{s} \mathrm{Bu}\right)_{3}$ (aluminum sec-butoxide) (b).

Corrosion inhibitors are incorporated into the coating in order to improve its corrosion resistance. Rare earth elements and particularly cerium are among those commonly used for that purpose and cerium has been found as an efficient cathodic inhibitor [13-16]. The objective of this work was to study the influence of cerium concentration within a sol-gel hybrid coating applied on martensitic stainless steel and developed from the system: glycidoxypropyltrimethoxysilane (GPTMS) and aluminum sec-butoxide $\mathrm{Al}\left(\mathrm{O}^{\mathrm{S}} \mathrm{Bu}\right)_{3}$. An investigation of the sol formulation and chemical mechanisms was made, kinetic of hydrolysis and condensation of alkoxysilanes has been followed with different cerium concentrations by liquid ${ }^{29}$ Si NMR spectroscopy to identify sol-gel mechanisms. Hydrophobic and adhesion properties of different coatings were studied respectively by contact angle measurement and "nanoscratchtest" device to verify cerium influence. Finally, the anti-corrosion properties of cerium doped or undoped hybrid organic-inorganic were investigated by electrochemical conventional techniques and an optimal cerium concentration was found: $0.01 \mathrm{M}$ and a correlation with ${ }^{29} \mathrm{Si}$ NMR results has been taken in evidence.

\section{Experimental procedure}

\subsection{Material}

Metallic substrates, CX13VD martensitic stainless steel SS (composition given in Table 1) $50 \mathrm{~mm} \times 25 \mathrm{~mm} \times 1 \mathrm{~mm}$ sizes samples are cleaned and pre-treated using several steps, after alkaline degreasing, chemical cleaning corresponds to: $1 \mathrm{~min}$ immersion in fluonitric acid $(\mathrm{pH}=1)$ maintained at $60^{\circ} \mathrm{C}$. Sample is finally washed in ethanol and dried in air.

\subsection{Sol and coating preparation}

Sols from which coatings were processed, were prepared by mixing glycidoxypropyl-trimethoxysilane (GPTMS) and aluminum tri-sec-butoxide $\mathrm{Al}\left(\mathrm{O}^{\mathrm{S}} \mathrm{Bu}\right)_{3}$ (formulas in Fig. 1) and distilled water and propanol in molar ratio 5:1:1:10. Then $\mathrm{Ce}\left(\mathrm{NO}_{3}\right)_{3} \cdot 6 \mathrm{H}_{2} \mathrm{O}$ was added to reach $0.001,0.005,0.01,0.05$ and $0.1 \mathrm{M} \mathrm{Ce}^{3+}$. The sol was stirred during $2 \mathrm{~h}$ at room temperature and matured for $24 \mathrm{~h}$ before deposition on the substrate to initiate the sol-gel reactions. They could schematically be divided into two steps, the first is a hydrolysis reaction (1) which aims to promote reactive hydroxyl groups reactive $\mathrm{M}-\mathrm{OH}$. The second step is the condensation reaction involving the alkoxide (2) or only the hydrolyzed species (3).

$\mathrm{M}(\mathrm{OR})_{n}+n \mathrm{H}_{2} \mathrm{O} \rightarrow \mathrm{M}(\mathrm{OH})_{n}+n \mathrm{ROH}$

$\mathrm{M}(\mathrm{OH})_{n}+\mathrm{M}(\mathrm{OR})_{n} \rightarrow(\mathrm{HO})_{n-1} \mathrm{M}-\mathrm{O}-\mathrm{M}(\mathrm{OR})_{n-1}+\mathrm{ROH}$

$\mathrm{M}(\mathrm{OH})_{n} \rightarrow(\mathrm{HO})_{n-1} \mathrm{M}-\mathrm{O}-\mathrm{M}(\mathrm{OH})_{n-1}+\mathrm{H}_{2} \mathrm{O}$
The sol-gel films were obtained by dip-coating procedure, using an immersion followed by a withdrawal at a controlled rate of $20 \mathrm{~cm} \mathrm{~min}^{-1}$. This withdrawal speed has been chosen in the range $\left[1-50 \mathrm{~cm} \mathrm{~min}^{-1}\right]$ because it corresponds to the more convenient covering in term of thickness (Landau and Levich law) and homogeneity of the film. After deposition, coated samples were dried in an oven at $100^{\circ} \mathrm{C}$ during $24 \mathrm{~h}$ to complete polymerization of the hybrid film.

\subsection{Characterization}

The viscosity of each sol was determined by a viscometer Rheomat RM100 of type Taylor-Couette flow at a shear in the range [600-966 s $\left.{ }^{-1}\right]$.

Kinetics of hydrolysis and condensation of alkoxysilanes were studied by liquid ${ }^{29} \mathrm{Si}$ NMR spectroscopy. The measurements were performed on a Brucker $400 \mathrm{MHz}$ spectrometer. NMR spectra were recorded with benzene like internal chemical shift reference. The chemical shifts were given in ppm relative to the internal reference.

Macrostructural properties of coatings were evaluated by SEM microscopy, observations were performed on samples with a JEOL JSM-6510LV apparatus.

Thickness measurements were performed with a fisher dualscope FMP20, this technique is commonly used for the determination of coating thicknesses such as paints.

Coating roughness is evaluated by white-light interferometry (Zygo Instruments).

Contact angle measurements were performed with water drop method using camera. Then the image was processed by a software package (windrop).

Scratch tests were performed using a Nano Scratch Tester CSM with a diamond indenter with conical geometry. The scratch test was carried out with progressive loading from 0 to $60 \mathrm{mN}$. After the scratch test, the changes in the mechanism of scratch and the critical loads were visualized by optical microscopy.

The electrochemical behavior of coating was evaluated by electrochemical impedance spectrometry (EIS) in $\mathrm{NaCl}$ $(0.1 \mathrm{M})+\mathrm{Na}_{2} \mathrm{SO}_{4}(0.04 \mathrm{M})$ solution. $\mathrm{A} \mathrm{KCl}_{\text {sat }}$ electrode, connected to the working solution, was used as reference electrode and a platinum tape as auxiliary electrode. All electrochemical experiments were performed after stabilization $(1 \mathrm{~h})$ of free open circuit potential. Electrochemical impedance spectra (EIS) ranging from $65 \mathrm{kHz}$ to $10 \mathrm{mHz}$ were carried with a $80 \mathrm{mV}$ sinusoidal perturbation signal to the corrosion potential with Solartron Instrument SI 1286 Electrochemical Interface potentiostat and a Solartron Instrument SI 1260 Impedance/Gain-Phase-analyser. All the electrochemical experiments were carried out to room temperature and the EIS diagrams were recorded for immersion times up to $24 \mathrm{~h}$.

\section{Results and discussion}

The scanning electron micrographs of substrate before and after cleaning are shown in Fig. 2 and it was revealed after surface preparation of metallic substrate, the martensitic microstructure with the presence of lamellas.

The viscosity of a sol undergoing hydrolysis and polycondensation is strongly dependent in time and is related to the size of particles. The larger the formed molecules, the higher the viscosity [17]. Fig. 3 shows the effect of cerium concentration on the viscosity of the sol aged for $24 \mathrm{~h}$ (just before deposition). An increase of viscosity can be observed with the increasing of cerium concentration. This is associated with the high hygroscopic character of cerium which absorbs the large amount of water trapped in the sol network [18]. 

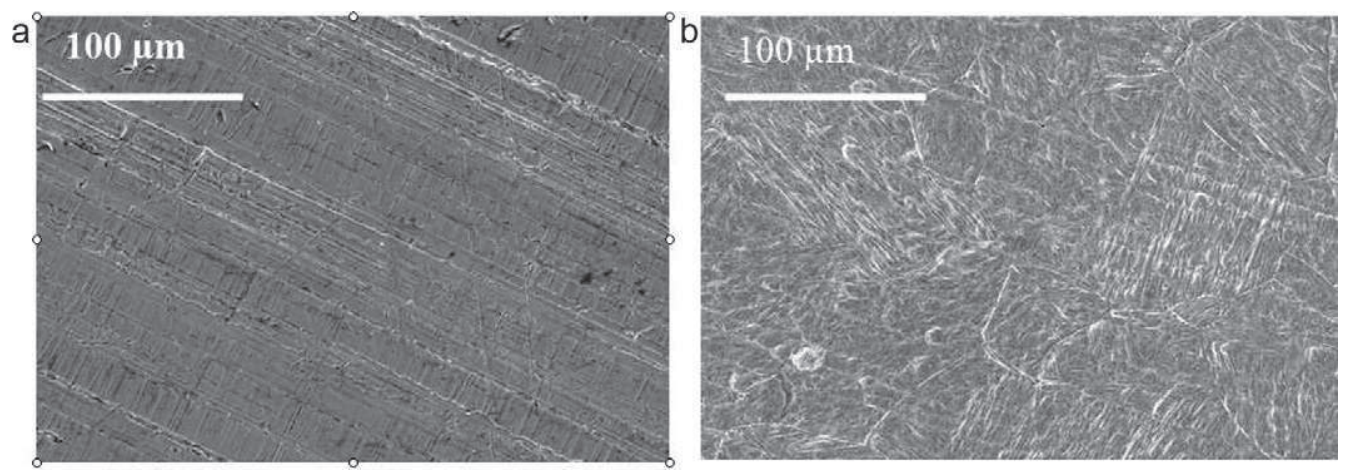

Fig. 2. SEM images of surface morphologies of X13VD stainless steel before (a) and after (b) cleaning.

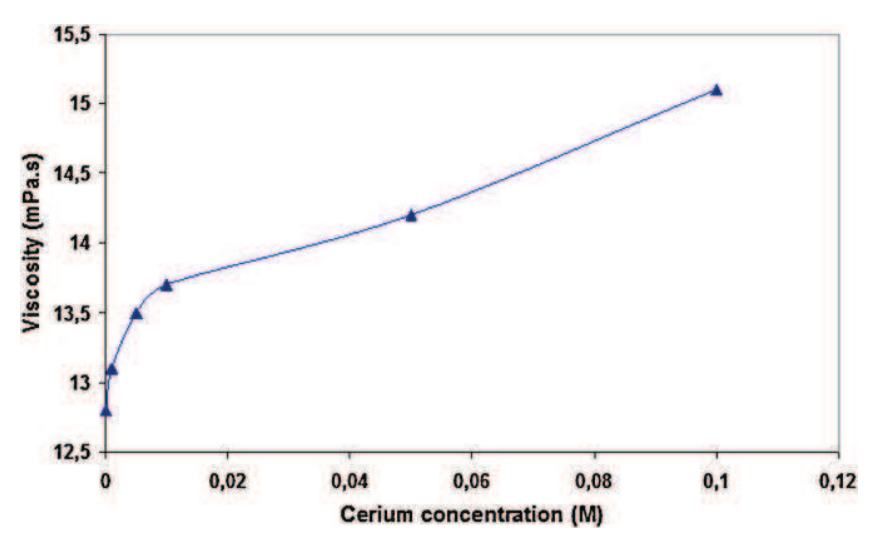

Fig. 3. Viscosity of sols with different concentrations of cerium.

For a better understanding of sol-gel mechanisms into the sols the work was on the bond involved in the reactions versus cerium concentration.

Liquid ${ }^{29} \mathrm{Si}$ NMR spectroscopy was used to investigate the chemical structure of the inorganic network just after the synthesis of sols $(0 \mathrm{~h})$ and after $(24 \mathrm{~h})$. During hydrolysis and condensation reactions, the silicon environment changes from $\mathrm{Si}-\mathrm{OR}$ to $\mathrm{Si}-\mathrm{OH}$ then to $\mathrm{Si}-\mathrm{O}-\mathrm{Si}$. Then, each condensation reaction, with the formation of a $\mathrm{Si}-\mathrm{O}-\mathrm{Si}$ oxo bridge induces a chemical shift of 8-10 ppm in the high field [19]. ${ }^{29} \mathrm{Si}$ NMR was carried out to follow the inorganic phase polymerization of each sol. The ${ }^{29} \mathrm{Si}$ presents the resonance signals at $-39,-49,-59$ and $-67 \mathrm{ppm}$, denoted $\mathrm{T}^{0}, \mathrm{~T}^{1}, \mathrm{~T}^{2}$ and $\mathrm{T}^{3}$ respectively $[20,21]$. The $\mathrm{T}$ species correspond to the silanes containing 0 , 1, 2 or 3 hydrolysed groups as shown in Fig. 4.

Fig. 5 shows the ${ }^{29} \mathrm{Si}$ NMR of different samples with various cerium concentrations at the initial state $(0 \mathrm{~h})$. At this reaction stage, $\mathrm{T}^{0}, \mathrm{~T}^{1}$ and $\mathrm{T}^{2}$, were the present species in all samples, no studied samples showed any signal of $\mathrm{T}^{3}$. Each peak which corresponded to $\mathrm{T}^{0}, \mathrm{~T}^{1}$ and $\mathrm{T}^{2}$ respectively had the same area for all samples, which means that the concentration of cerium had no real influence on the condensation of sol-gel network and each specie was present in the same concentration. However a slight

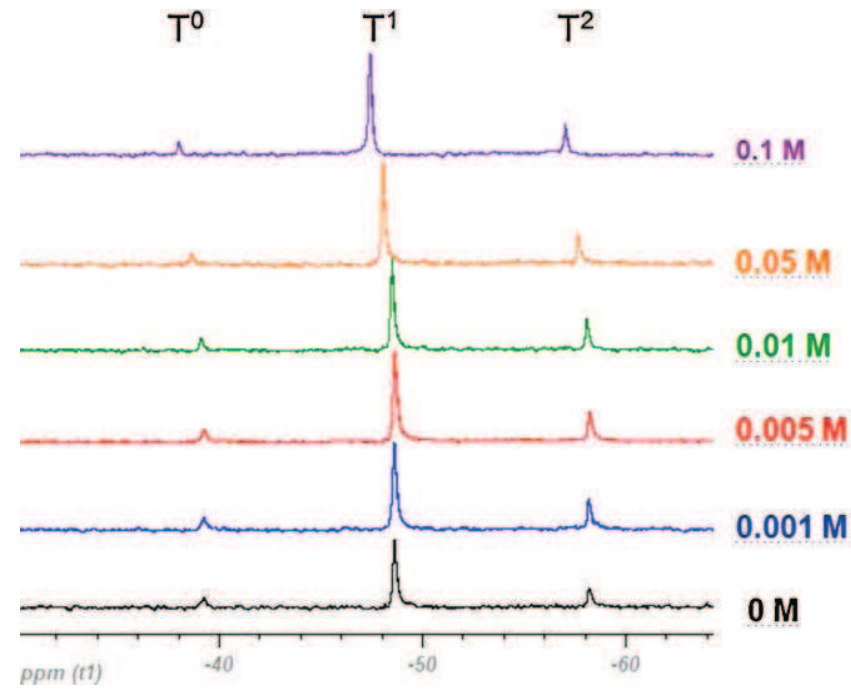

Fig. 5. Liquid ${ }^{29} \mathrm{Si}$ NMR spectra of sol with different cerium concentrations $(0 \mathrm{~h})$.

displacement of signals in the low field was observed for sols with higher cerium concentration $(0.05$ and $0.1 \mathrm{M})$. Fig. 6 shows the ${ }^{29} \mathrm{Si}$ NMR of same samples after a sol-gel reaction at $24 \mathrm{~h}$ just before the deposition step. No studied sample showed signal of the free trialkoxysilane precursor $\mathrm{T}^{0}$ and peak area corresponding to specie $\mathrm{T}^{2}$ increased for all samples. It means that the condensation increased in the same way for the sols with different cerium concentrations. This phenomenon is still observed for sols which contained cerium concentration of 0.05 and $0.1 \mathrm{M}$. For example, the focus on the shift of $\mathrm{T}^{2}$ specie (Fig. 7), this was clearly observed for cerium concentration higher than $0.01 \mathrm{M}$. Furthermore, on this zoom, the presence of satellite peaks can be underlined. They also correspond to $\mathrm{T}^{2}$ bonds but for different species in the second sphere of coordination. In all cases (mean peak and satellite peaks) the shift from 0.01 to 0.1 is preserved. In the literature [22,23], for other silane based matrix with TEOS it can be due to the electronegative effect of Ce(III) which can reduce the local diamagnetic shielding in the vicinity of

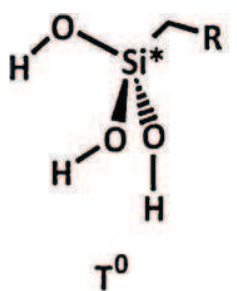

$\mathrm{T}^{0}$

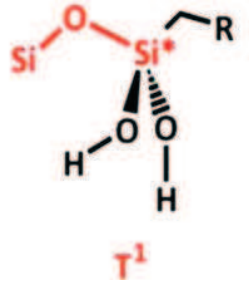

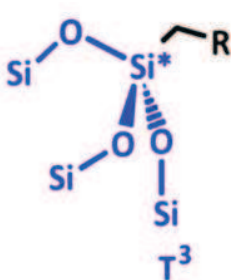

Fig. 4. Schemes of $\mathrm{T}$ species. 


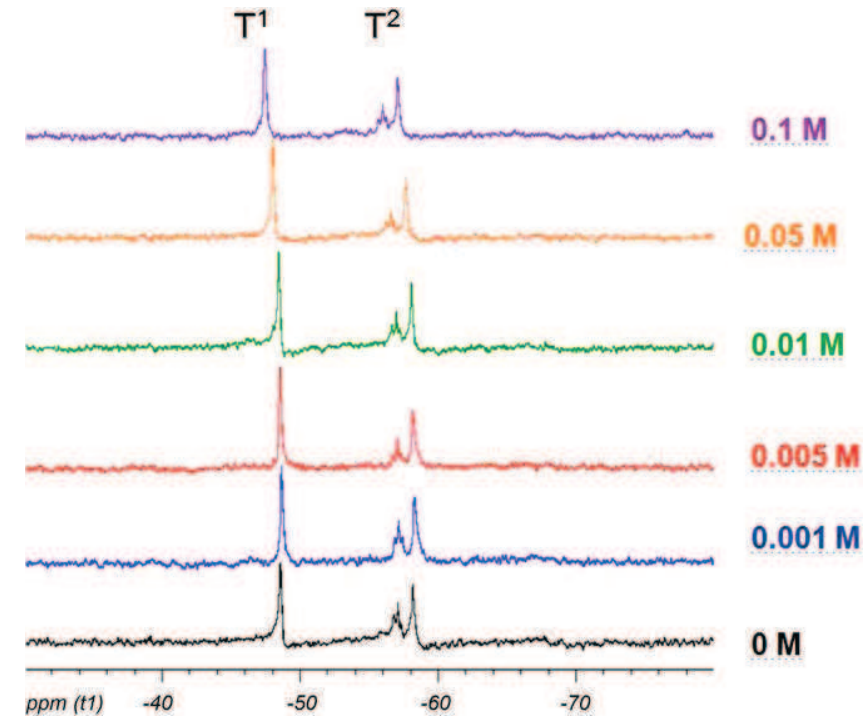

Fig. 6. Liquid ${ }^{29} \mathrm{Si}$ NMR spectra of sol with different cerium concentrations (24h)

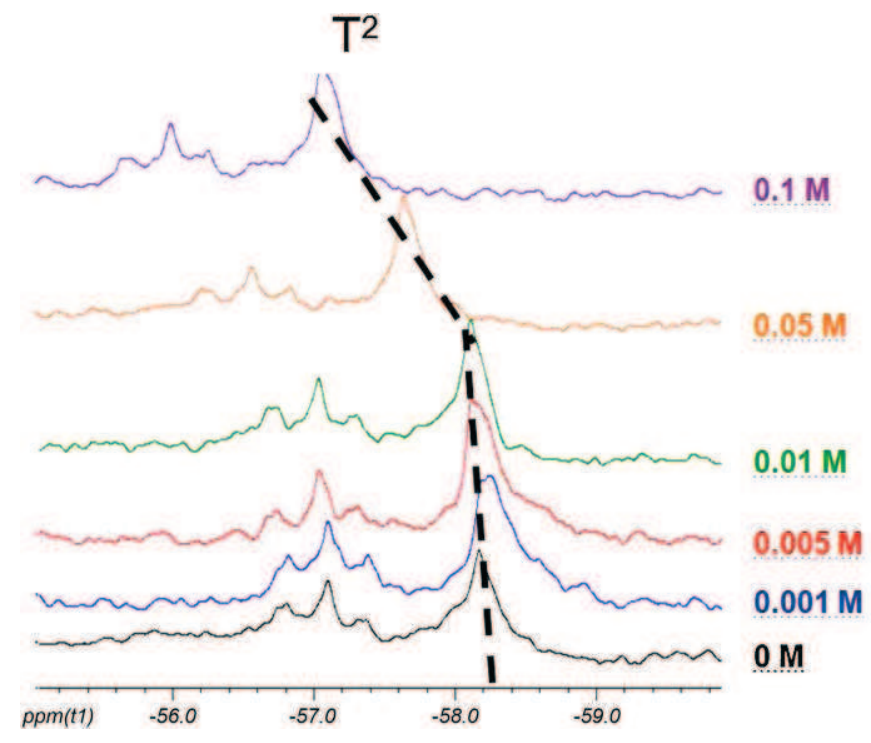

Fig. 7. Liquid ${ }^{29} \mathrm{Si}$ NMR spectra of sol with different concentrations of cerium ( $24 \mathrm{~h}$ ) focus on $10 \mu \mathrm{m}$. the attached protons. Cerium had no influence on condensation of network sol-gel but a large quantity of this dopant $(>0.01 \mathrm{M})$ can change the chemical structure of sol-gel network.

Now it is interesting to characterize the coatings elaborated by dip-coating with the sols studied previously. Fig. 8 presents a SEM micrograph of a surface and cross section of sol-gel coating without cerium deposited X13VD substrate. At this scale, the coating is homogeneous, covering, crack-free and adherent to the substrate. The average thickness of coating, estimated by the cross section analysis (Fig. 8b) is about 5-6 $\mu \mathrm{m}$. The leveling character of this film can be underlined by white light interferometry (Fig. 9) and the surface roughness $R_{\mathrm{a}}$ decreases $(0.42 \rightarrow 0.17 \mu \mathrm{m})$.

Thickness measurements performed by fisher dualscope for hybrid coatings with different cerium concentrations and are reported in Table 2 . The values and their accuracy cannot show a real influence on the layer thickness although the cerium presence has increased the sol viscosity, parameter directly correlated to the layer thickness [24].

The hydrophobicity was evaluated from contact angle measurement of a water drop on hybrid coating. The obtained values versus the cerium concentration are given in Fig. 10. This graph shows a slight tendency of the contact angle increase with the increase of cerium concentration, from $75^{\circ}$ for a coating without cerium until about $80^{\circ}$ for coatings with higher cerium concentration. This value underlines the hydrophobic character of coating and improves the tightness toward water which is an important characteristic for anticorrosion properties.

Anticorrosion properties depend on intrinsic properties of the coatings but also on bonds established with the substrate and as a consequence on the adhesion. To investigate the influence of cerium on the coatings adhesion to stainless steel substrates scratch tests with increasing load were performed on the various samples. Different critical loads, indicating changes in the mechanism of scratch were defined [25-27] as it can be seen in Fig. 11:

- CL 0: Plastic deformation

- CL 1: Brittle fracture

- CL 2: Delamination

The different critical load values ( $\mathrm{mN}$ ) of the hybrid sol-gel coating which contain different inhibitor concentrations were showed in Fig. 12. It was observed that this concentration had no significative influence on the adhesion properties of coatings. This graph shows that for all cerium concentrations in the coating, the two critical loads CL 0, CL 1 stayed almost unchanged considering the accuracy of the measurements because the curves which represent each critical load are quite stable. For the critical load CL 2, a slight decrease of this load can be underlined, probably due to a lower delamination resistance for high cerium content. Then to try
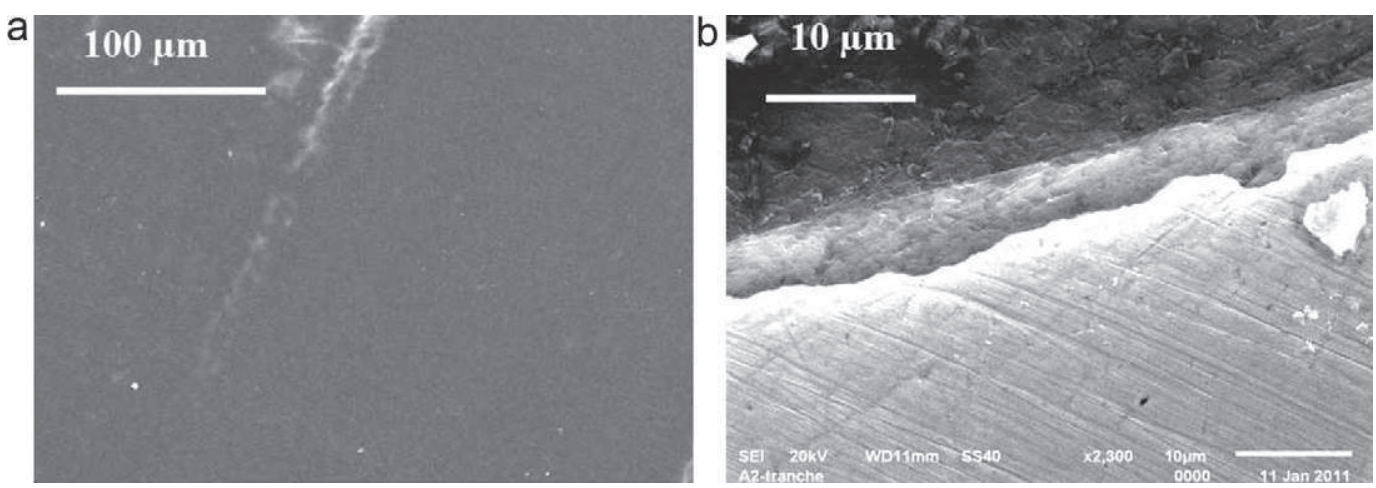

Fig. 8. SEM observations of hybrid coating deposited on X13VD: surface (a) and cross section (b). 

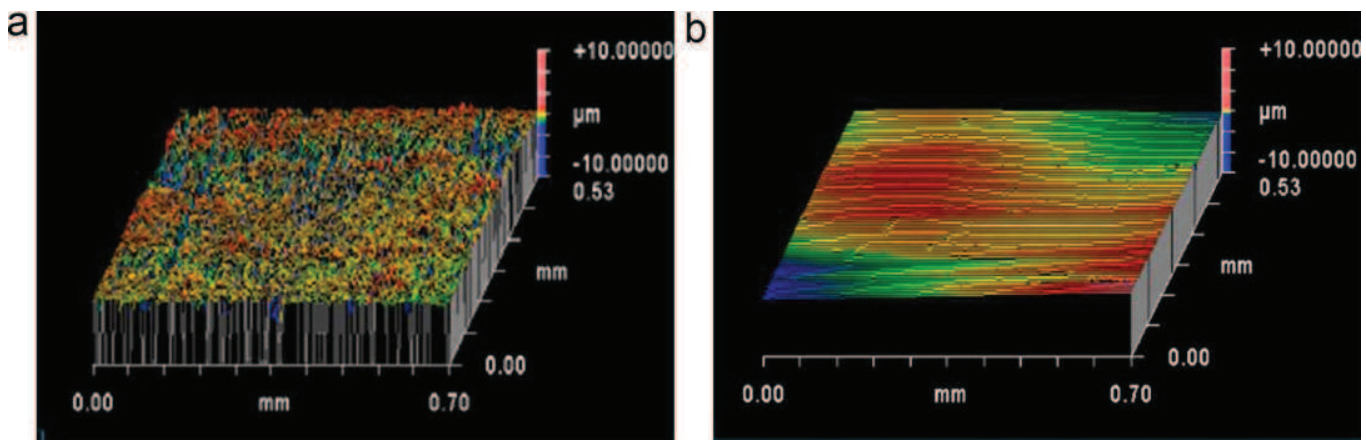

Fig. 9. 3D topographic analysis of the surfaces of (a) X13VD stainless steel and (b) hybrid coating on X13VD, from a white light interferometer.

Table 2

Hybrid coating thickness obtained for different concentrations of cerium.

\begin{tabular}{llllll}
\hline Cerium concentration $(\mathrm{M})$ & 0 & 0.001 & 0.005 & 0.01 & 0.05 \\
Thickness $(\mu \mathrm{m})$ & $5.73 \pm 0.6$ & $5.35 \pm 0.7$ & $6.01 \pm 0.8$ & $5.61 \pm 0.5$ & $5.77 \pm 0.7$ \\
\hline
\end{tabular}

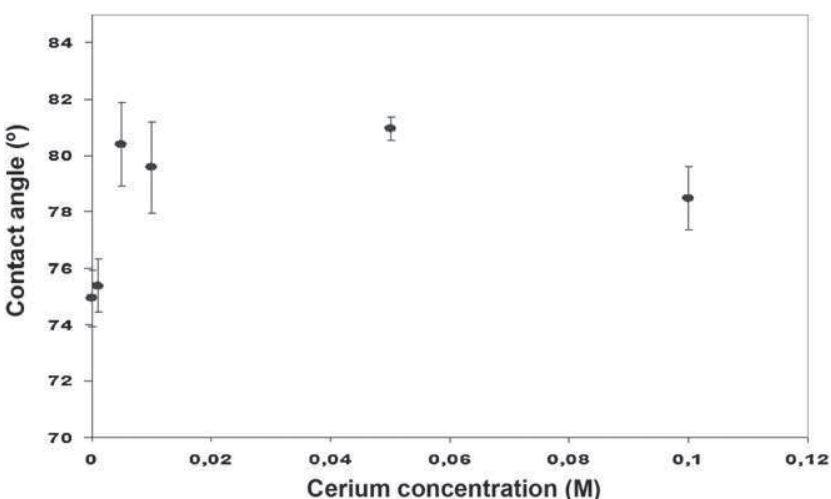

Fig. 10. Contact angle values of a water drop on hybrid coating on X13VD with different cerium concentrations.

to understand why cerium content plays a role on sol properties, it was planned to determine the cerium content influence on the corrosion resistance of coatings.

The electrochemical impedance spectroscopy (EIS) is one of the most commonly technique used for investigation and prediction of the anticorrosion protection [28,29]. This powerful method allows not only a comparison between performances of different systems but also can give key information on kinetics mechanisms of the coating damage and the corrosion activity during immersion in the corrosion media. In this work EIS was used to investigate the effect of cerium concentration in sol on the corrosion behavior of the

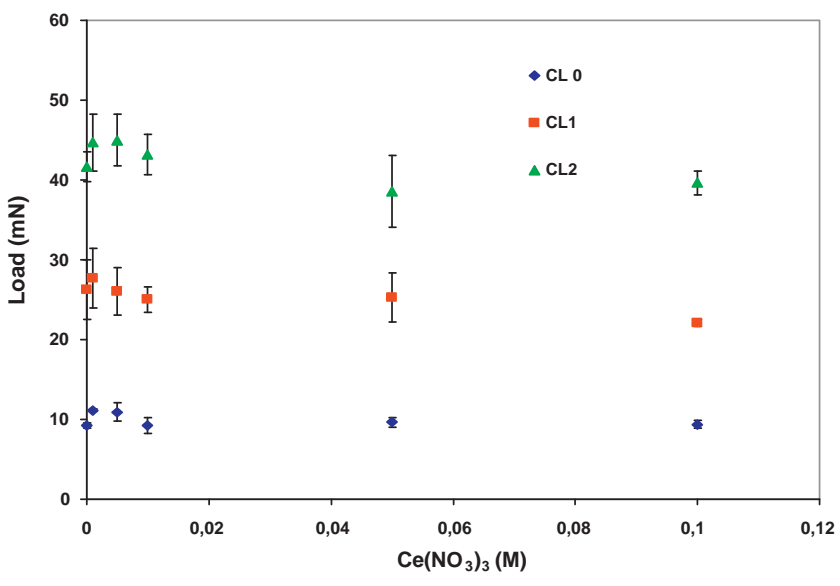

Fig. 12. Critical loads for hybrid coating on X13VD stainless steel with different cerium concentrations.

$\mathrm{X} 13 \mathrm{VD}$ substrates coated in corrosive solution $\left(\mathrm{NaCl} 0.1 \mathrm{M}+\mathrm{Na}_{2} \mathrm{SO}_{4}\right.$ $0.04 \mathrm{M}$ ). EIS diagrams with X13VD stainless steel and hybrid coated samples were obtained after stabilization of the corrosion potential and for different immersion times.

Fig. 13 shows the EIS plots in Bode representation obtained from the sol-gel hybrid coating without cerium compared to X13VD substrate after respectively $1 \mathrm{~h}$ and $24 \mathrm{~h}$ immersion. For X13VD substrate, the electrochemical impedance diagrams obtained after different immersion times are characterized by two time constants

\section{Load increases}
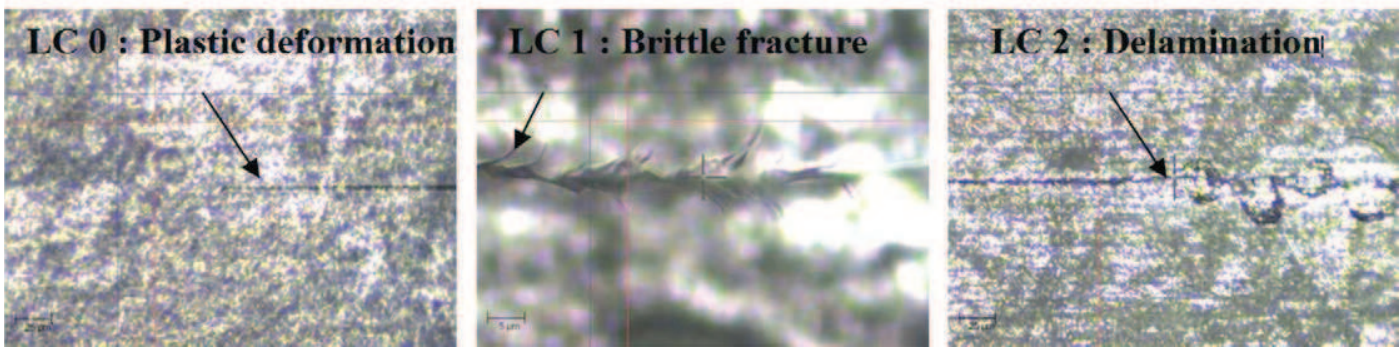

Fig. 11. Optical micrographs of critical loads during a scratch test. 

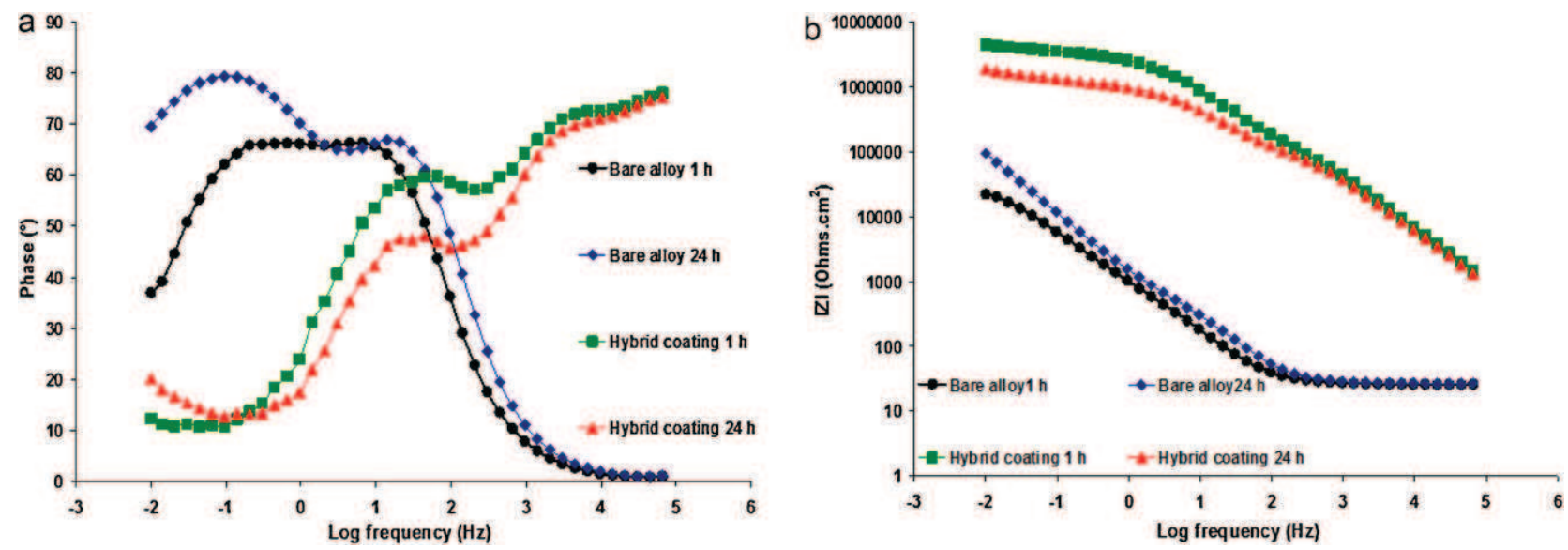

Fig. 13. Bode phase (a) and modulus impedance (b) plots for X13VD stainless steel uncoated and hybrid coating without cerium on X13VD stainless steel in NaCl $(0.1 \mathrm{M})+\mathrm{Na}_{2} \mathrm{SO}_{4}(0.04 \mathrm{M}) 1 \mathrm{~h}$ and $24 \mathrm{~h}$ immersion.

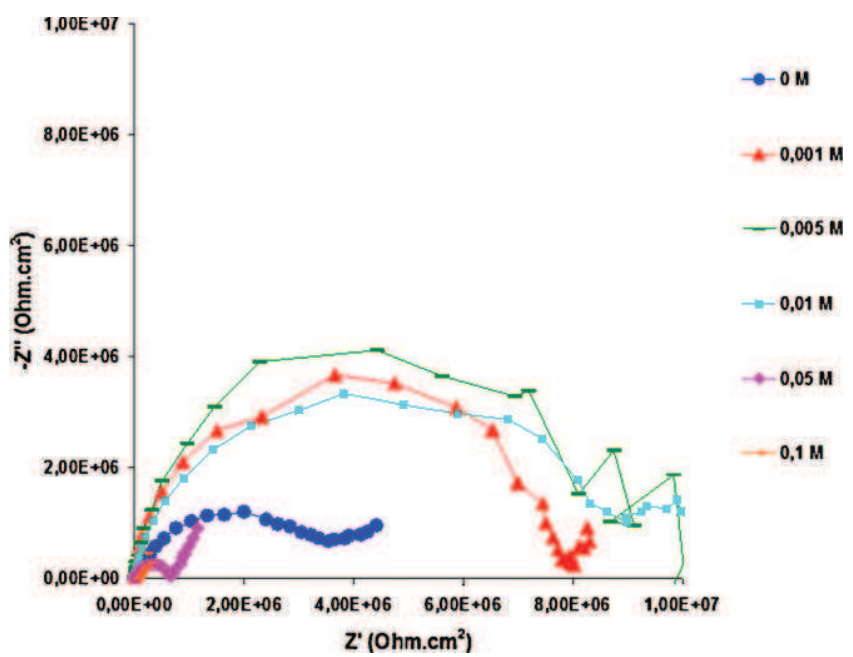

Fig. 14. Nyquist plots for hybrid coating on $\mathrm{X} 13 \mathrm{VD}$ stainless with different concentrations of cerium in $\mathrm{NaCl}(0.1 \mathrm{M})+\mathrm{Na}_{2} \mathrm{SO}_{4}(0.04 \mathrm{M}) 1 \mathrm{~h}$ immersion.

(Fig. 13a). The first time constant $[0-1000 \mathrm{~Hz}]$ is independent of the immersion time and the second $[0.01-1 \mathrm{~Hz}]$ one is better defined for increasing immersion times. According to literature [30,31] if the bar steel is considered, the time constant at high frequency is attributed to charge transfer process and the time constant at the low frequency is correlated with the redox processes taking place into the passive film. The increase of impedance modulus in the low frequency range (Fig. 13b) when immersion time is longer can be interpreted by the improvement of the protection of the passive film. For the hybrid coating deposited on the substrate (Fig. 14a) after $1 \mathrm{~h}$ immersion, two time constants can be then observed, one for the high frequency area (HF) [1000-65000 Hz] which can be attributed to the hybrid coating properties: barrier effect which limits charge transfer process and an other time constant at medium frequency (MF) $[1-1000 \mathrm{~Hz}]$ where an inflexion of the curve is observed which can be associated to the hybrid film permeability. On hybrid coating after $24 \mathrm{~h}$ immersion $(10 \mathrm{mHz})$, the appearance of a third time constant was observed at low frequency (LF). It is probably due to the formation of a passivation layer at the interface between the hybrid coating and the substrate. This layer can result from the reaction between stainless steel and the electrolyte, which diffuses into the coating. It is the same phenomenon that for uncoated substrate but however this contribution remained relatively low due to the hybrid barrier effect. The high modulus impedance (Fig. 14b) of coated stainless steel slightly decreased after $24 \mathrm{~h}$ of immersion and indicates the beginning of the film damage; however the performances are still greatly superior to these of the passivated substrate, so this proves the good barrier effect of the sol-gel coating.

Fig. 14 shows EIS measurements with Nyquist plot for hybrid sol-gel coatings containing different concentrations of cerium after $1 \mathrm{~h}$ immersion. When cerium was added in coating to $0.01 \mathrm{M}$, it was clearly observed an increase of the capacitive loop, it means that the barrier effect was improved with low cerium content in the range $[0-0.01 \mathrm{M}]$. When cerium content is higher than $0.01 \mathrm{M}$, another behavior was taken in evidence: an important drop of the barrier effect with a decrease of capacitive loops, but this time it is not due to a decrease of the coating thickness because the sols with cerium content of 0.05 and $0.1 \mathrm{M}$ have a viscosity higher (Fig. 3 ). The deterioration of barrier properties of the film can be attributed to the modification in the hybrid films network by the Ce ions incorporation, as it was mentioned before by other others [32].

Fig. 15 shows EIS measurements in the Bode representation (phase and modulus) in order to compare corrosion performance for hybrid sol-gel coatings containing different cerium concentrations after $1 \mathrm{~h}$ immersion. When cerium was added in sol until a concentration reaching $0.01 \mathrm{M}$, it was clearly observed on the curves (Fig. 15a), an improvement of the barrier effect and a decrease of the permeability of hybrid coating because the inflection of the curve at medium frequency (MF) was shifted to lower frequency. For higher cerium concentrations ( 0.05 and $0.1 \mathrm{M})$, the corrosion performances of these coatings clearly collapsed and the inflection of the curve at MF was shifted to higher frequencies. These coatings are more permeable and the electrolyte penetrates the coatings more easily to react with the substrate and to form the passivation layer because the constant time at low frequency, characteristic of this passivation layer, is more significative. The impedance modulus (Fig. 15b) increases for low cerium content $(<0.01 \mathrm{M})$ and sharply decreases for these same cerium concentrations in the sol-gel coating. Fig. 16 shows impedance modulus at low frequency $(10 \mathrm{MHz})$ versus cerium concentration. This modulus is characteristic of corrosion protection of the whole system: hybrid coating and reactivity with the substrate. It was also observed that this modulus increased when cerium concentration reached a value between 0.005 and $0.01 \mathrm{M}$. Then, for higher inhibitor concentrations, the modulus highly decreased and the coating became less protector than coating without cerium. The same remark may be made for coating with different inhibitor concentrations after an immersion of $24 \mathrm{~h}$ in the corrosive solution. Bode representation with phase (Fig. 17) and impedance 

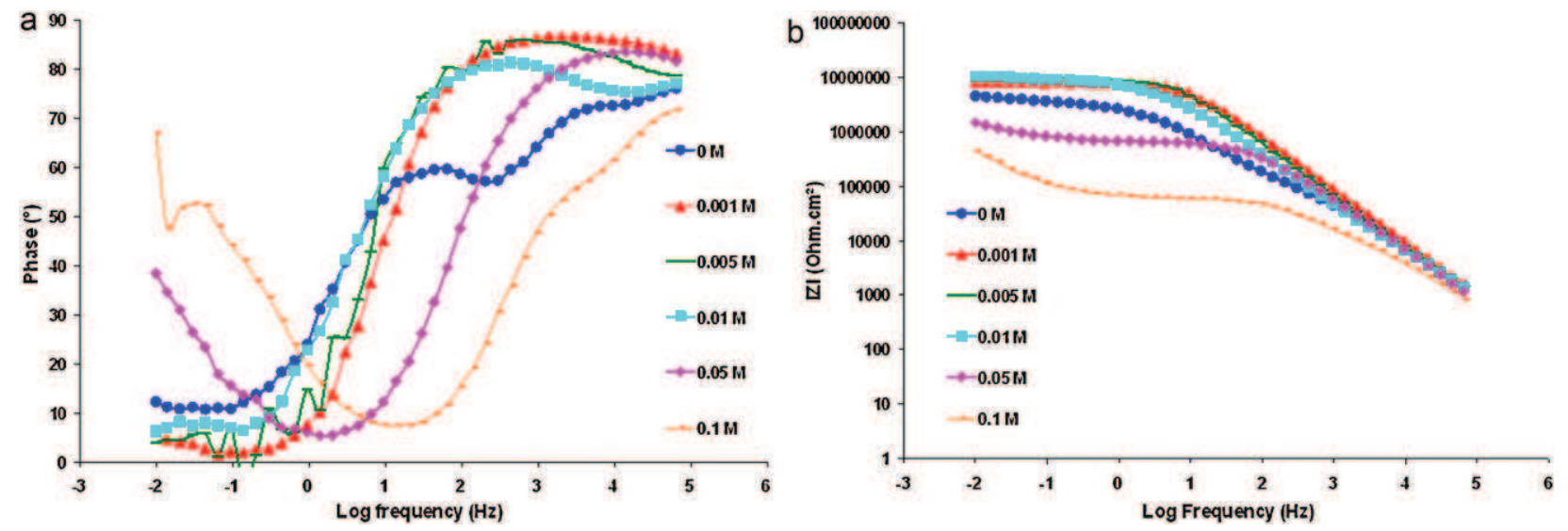

Fig. 15. Bode phase (a) and impedance modulus (b) plots for hybrid coating on X13VD stainless with different concentrations of cerium in $\mathrm{NaCl}(0.1 \mathrm{M})+\mathrm{Na}_{2} \mathrm{SO}_{4}(0.04 \mathrm{M}) 1 \mathrm{~h}$ immersion.

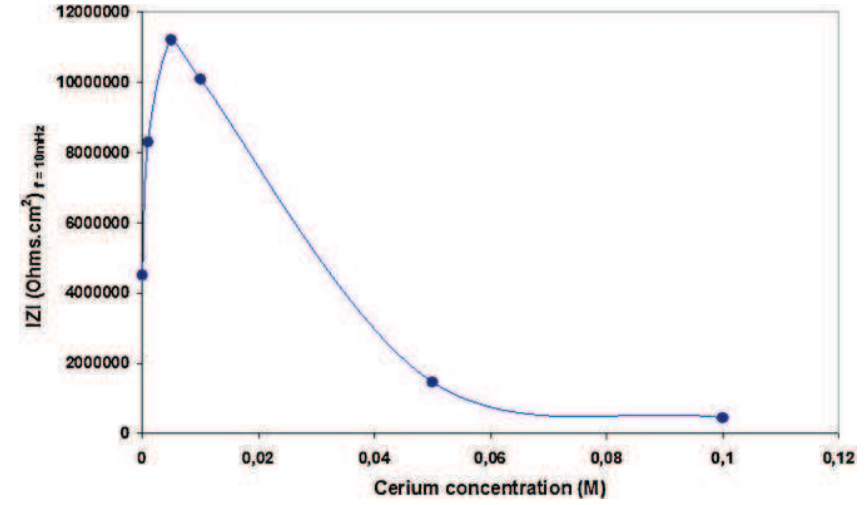

Fig. 16. Impedance modulus $(f=10 \mathrm{mHz})$ with different concentrations of cerium in $\mathrm{NaCl}(0.1 \mathrm{M})+\mathrm{Na}_{2} \mathrm{SO}_{4}(0.04 \mathrm{M}) 1 \mathrm{~h}$ immersion.

modulus (Fig. 18), shows that the optimal cerium concentration in the coating corresponds to a value of $0.01 \mathrm{M}$.

Taken into account these results, one key point is confirmed: the existence of a threshold concentration of cerium corresponding to $0.01 \mathrm{M}$. So, it is possible to try to correlate these corrosion results with chemical displacements obtained by liquid ${ }^{29} \mathrm{Si} N \mathrm{NR}$ spectroscopy for sols with a high cerium concentration. These shifts correspond to the important collapse in anti-corrosion properties of sol-gel hybrid coating. Cerium had not any influence on condensation network silane but a large quantity of this dopant $(>0.01 \mathrm{M})$ can change the chemical structure of hybrid network. There is an

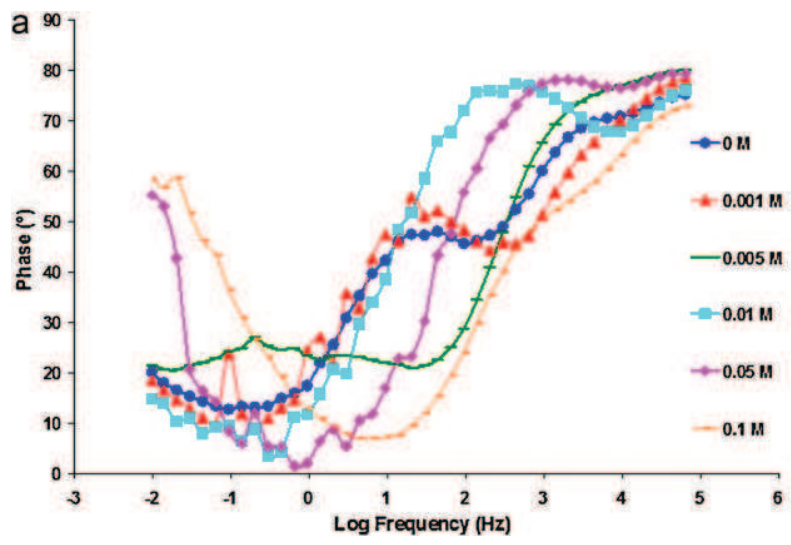

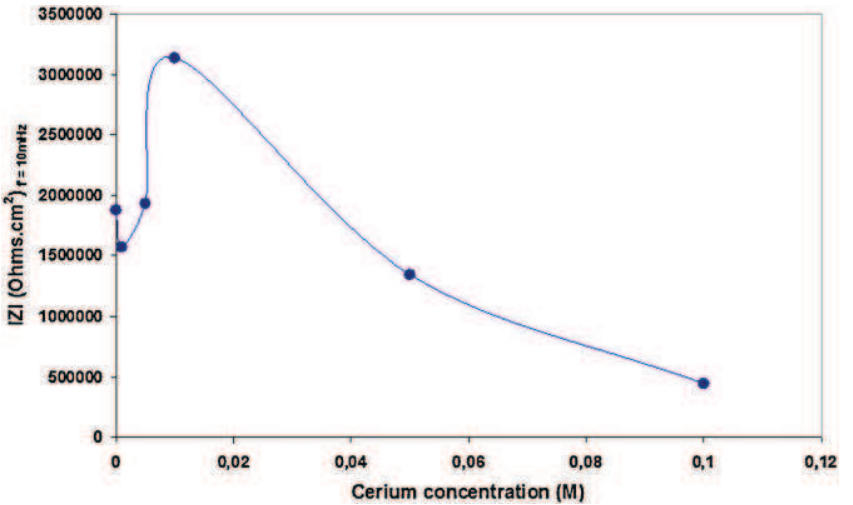

Fig. 18. Impedance modulus $(f=10 \mathrm{mHz})$ for hybrid coating on $\mathrm{X} 13 \mathrm{VD}$ stainless with different cerium concentrations in $\mathrm{NaCl}(0.1 \mathrm{M})+\mathrm{Na}_{2} \mathrm{SO}_{4}(0.04 \mathrm{M}) 24 \mathrm{~h}$ immersion.

ability to create new connection ( $\mathrm{Ce}-\mathrm{Al})$ with aluminum from the ASB of the matrix which could destabilize the hybrid network and also reduce the resistance toward corrosion of coatings. It will then be interesting to study the chemical structure of sol-gel hybrids at solid state with techniques such as solid ${ }^{29} \mathrm{Si}$ and ${ }^{13} \mathrm{C}$ NMR characterization and Raman spectrometry in order to better understand now the influence of cerium directly on coating properties (these experiments are now in progress).

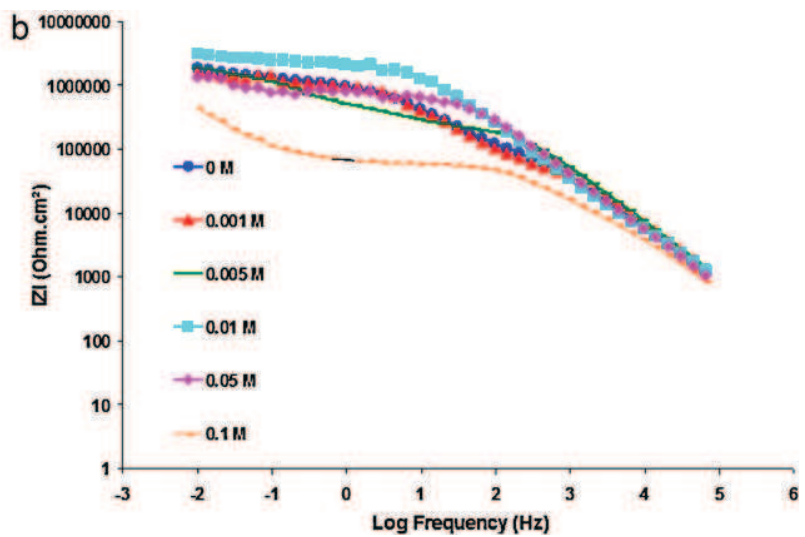

Fig. 17. Bode phase (a) and impedance modulus (b) plots for hybrid coating on $\mathrm{X} 13 \mathrm{VD}$ stainless with different cerium concentrations in $\mathrm{NaCl}(0.1 \mathrm{M})+\mathrm{Na} 2 \mathrm{SO} 4(0.04 \mathrm{M}) 24 \mathrm{~h}$ immersion. 


\section{Conclusion}

The influence of cerium concentration on behavior against corrosion of hybrid sol-gel coating on martensitic X13VD stainless steel has been investigated. The increase of cerium content improved hydrophobic character of coating and its tightness toward water. Electrochemical impedance spectroscopy showed an optimal cerium concentration of $0.01 \mathrm{M}$ in the hybrid layer. Besides, the increase of cerium concentration above $0.01 \mathrm{M}$ decreased the barrier effect of sol-gel coating. The coatings were performed by scratch tests, and no significative cerium influence has been proved on the adhesion properties of coatings to the martensitic substrate; so a direct correlation between anticorrosion and adhesion performances of sol-gel coating is not possible. Liquid ${ }^{29} \mathrm{Si} \mathrm{NMR}$ spectroscopy was then carried out to determinate the cerium influence on sol condensation. It was shown that an excess of cerium $(>0.01 \mathrm{M})$ lead to a chemical shift of $\mathrm{T}$ species and can change the chemical structure of sol-gel network. Therefore a reduction of corrosion resistance of coatings up was noted to the same cerium concentration $(0.01 \mathrm{M})$.

\section{Acknowledgments}

This work was carried out in the framework of the ARCAM project, with the financial support of DGCIS, Regions Aquitaine, Auvergne and Midi-Pyrénées. The authors thankfully acknowledge the partners of the project: Ratier-Figeac, Aubert\&Duval, Olympus, the Mechanical and Engineering Institute of Bordeaux, the Materials Department of ICAM and the Institute CARNOT CIRIMAT.

\section{References}

[1] M.R. Ryan, D.E. Williams, R.J. Chater, B.M. Hutton, D.S. McPhail, Nature 415 (2002) 770 .

[2] I. Betova, M. Bojinov, T. Laitinen, K. Makela, P. Pohjanne, T. Saario, Corros. Sci. 44 (2002) 2675.

[3] Toxicological Profile for Chromium, ATDSR/Tp-88/10, Agency for Toxic Substances, US Public Service, Washington, DC, 1989.
[4] M. Guglielmi, J. Sol-Gel Sci. Technol. 8 (1997) 443.

[5] D.C.L. Vasconcelos, J.A.N. Carvalho, M. Mantel, W.L. Vasconcelos, J. Non-Cryst. Solids 273 (2000) 135.

[6] A. Nazeri, P.P. TrzaskomaPaulette, D. Bauer, J. Sol-Gel Sci. Technol. 10 (1997) 317.

[7] J. Masalski, J. Gluszek, J. Zabrzeski, K. Nitsch, P. Gluszek, Thin Solid Films 349 (1999) 186.

[8] F. Perdomo, P.D. Lima, M.A. Aegerter, L.A. Avaca, J. Sol-Gel Sci. Technol. 15 (1999) 87.

[9] V.H.V. Sarmento, M.G. Schiavetto, P. Hammer, A.V. Benedetti, C.S. Fugivara, P.H. Suegama, S.H. Pulcinelli, C.V. Santilli, Surf. Coat. Technol. 204 (2010) 2689-3270.

[10] E. Roussi, A. Tsetsekou, D. Tsiourvas, A. Karantonis, Surf. Coat. Technol. 205 (2011) 3235-3244.

[11] R.T. Sakai, F.M. Di, L. da Cruz, H.G. de Melo, A.V. Benedetti, C.V. Santilli, P.H. Suegama, Prog. Org. Coat. 74 (2012) 288-301.

[12] T.P. Chou, C. Chandrasekaran, G.Z. Cao, J. Sol-Gel Sci. Technol. 26 (2003) 321.

[13] A. Pepe, M. Aparicio, S. Ceré, A.J. Durán, J. Non-Cryst. Solids 348 (2004) 162-171.

[14] M.A. Arenas, J.J. de Damborena, Electrochem. Acta 48 (2003) 3693-3698.

[15] F. Andreatta, L. Paussa, A. Lanzutti, N.C. Rosero Navarro, M. Aparicio, Y. Castro, A. Duran, D. Ondratschek, L. Fedrizzi, Prog. Org. Coat. 72 (2011) 3-14.

[16] C. Motte, M. Poelman, A. Roobroeck, M. Fedel, F. Deflorian, M.-G. Olivier, Prog. Org. Coat. 74 (2012) 326-333.

[17] L.L. Hench, J.K. West, Chem. Rev. 90 (1990) 33-72.

[18] X. Zhong, Q. Li, J. Hu, X. Yang, Prog. Org. Coat. 69 (2010) 52-56.

[19] M. Feuillade, C. Croutxé-Barghorn, C. Carré, J. Non-Cryst. Solids 352 (2006) 34-341.

[20] L.B. Toung, W.S. Trahanovsky, J. Am. Chem. Soc. 91 (1969) 5060.

[21] F.L.S. Purgato, J.R. Romero, J. Catal. 209 (2000) 394.

[22] D.L. Pavia, G.R. Lampman, G.S. Kriz, Introduction to Spectroscopy, 2nd ed., Harcourt Brace, London, 1996.

[23] S. Aubonnet, C.C. Perry, J. Alloys Compd. 300-3001 (2000) 224-229.

[24] L.D. Landau, B.G. Levich, Acta Physiochim. U. R. S. S. 17 (1942) 42-54.

[25] A. Kupicka, Prog. Org. Coat. 46 (2003) 32.

[26] F. Bondioli, R. Taurino, A.M. Ferrari, J. Colloid Interface Sci. 334 (2009) 195-201.

[27] S.M. Noh, J.W. Lee, J.H. Nam, J.M. Park, H.W. Jung, Prog. Org. Coat. 74 (2012) 192-203.

[28] S.V. Lamaka, M.L. Zheludkevich, K.A. Yasakau, R. Serra, S.K. Poznyak, M.G.S. Ferreira, Prog. Org. Coat. 58 (2007) 127-135.

[29] M.L. Zheludkevich, K.A. Yasakau, A.C. Bastos, O.V. Karavai, M.G.S. Ferreira, Electrochem. Commun. 9 (2007) 2622-2628.

[30] L. Freire, M.J. Carmezin, M.G.S. Ferreira, M.F. Montemor, Electrochim. Acta 55 (2010) 6174-6181.

[31] C.M. Abreu, M.J. Cristóbal, R. Losada, X.R. Nóvoa, G. Pena, M.C. Pérez, Electrochim. Acta 51 (2006) 1881-1890.

[32] C.F. Malfatti, T.L. Menezes, C. Radtke, J. Esteban, F. Ansart, J.P. Bonino, Mater. Corros. 62 (2011) 9999. 